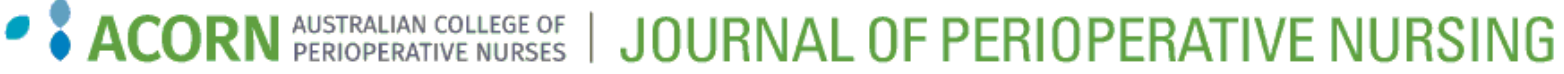

Volume 30 | Issue 2

Article 2

6-1-2017

\title{
A selected international appraisal of the role of the Non-Medical Surgical Assistant
}

Follow this and additional works at: https://www.journal.acorn.org.au/jpn

Part of the Health Services Administration Commons, Health Services Research Commons, Perioperative, Operating Room and Surgical Nursing Commons, and the Surgery Commons

(c) (†)

This work is licensed under a Creative Commons Attribution 4.0 License.

\section{Recommended Citation}

Hains, Toni; Strand, Haakan; and Turner, Catherine (2017) "A selected international appraisal of the role of the Non-Medical Surgical Assistant," Journal of Perioperative Nursing: Vol. 30 : Iss. 2 , Article 2.

Available at: https://doi.org/10.26550/2209-1092.1015

https://www.journal.acorn.org.au/jpn/vol30/iss2/2

This Article is brought to you for free and open access by Journal of Perioperative Nursing. It has been accepted for inclusion in Journal of Perioperative Nursing by an authorized editor of Journal of Perioperative Nursing. 


\section{Author}

Toni Hains

MClinSc (PNSA), MNPractSt, RN

Haakan Strand

PhD, MNPractSt, RN

Catherine Turner

PhD, RN

\section{Corresponding author}

Toni Hains

School of Nursing, Midwifery and

Social Work

Level 3, Chamberlain Building,

The University of Queensland

St Lucia, QLD 4072

s4277231@student.uq.edu.au

\section{A selected international appraisal of the role of the Non-Medical Surgical Assistant}

\section{Introduction}

The term Non-Medical Surgical Assistant (NMSA) is not widely acknowledged in Australia but is used to describe the role of clinicians without a medical degree or qualification who provide clinical services during the perioperative phase of a patient's journey. The role of NMSA has many configurations internationally and not all NMSA roles arise from a nursing platform. To date, the implementation of many Advanced Practice Nurse (APN) roles have lacked educational support or professional direction. The literature supports the standardisation of APN roles where they are regulated by the profession and attained through an appropriate tertiary level qualification ${ }^{2,3}$. In this paper, we review characteristics of the roles of the NMSAs in the United States of America, Canada, the United Kingdom and New Zealand, countries that have similar standards for practice to Australia and provide a similar standard of health care. We will discuss implications for perioperative nurses and make recommendations for a future approach which formalises the role of the NMSA for the Australian context.

\section{Background}

While the title NMSA is not globally accepted, the role is typically associated with a clinician who delivers care that would otherwise be provided by medical practitioners. Care may incorporate elements of preoperative assessment and postoperative care encompassing pain management, wound care and discharge planning. The intraoperative phase cares for patients when they are highly vulnerable. This care includes application of surgical skills, dexterity and technical knowledge of anatomy, instrumentation and equipment 4,5 .

The increase in international discussion about the role of the NMSA can be credited to factors such as changes in health care workforce regulation (e.g. European Working Time Directive limiting training doctors to a 48-hour week) $)^{6,7}$, medical professionals seeking a better worklife balance, or the feminisation of the medical profession leading to an increase in the casualisation of the workforce ${ }^{8,9}$.

\section{Method}

Aims and objectives

The objective of this paper was to investigate the international NMSA role and differentiate levels of autonomy and professional recognition. These elements can then be applied to the NMSA role as it evolves in Australia.

\section{Scope}

The literature was searched for international papers that discussed:

- role titles and descriptions of NMSAS

- prerequisites for entry into programs for NMSAs

- programs of education including accreditation standards

- standards of practice for NMSAs

- educational attainment and qualifications required for NMSAs 
- professional governance, regulation and representation for NMSAs

- role differentiation between NMSAs, nurses and other health professionals

- autonomy and scope of practice issues.

\section{Search strategy}

A search of the databases CINAHL, Medline, Web of Science, Proquest and Pubmed was conducted. Papers were required to be published in English after 1990. Examples of terms searched for include:

- non-medical surgical assistant

- Perioperative Nurse Surgeon's Assistant

- Registered Nurse First Assistant

- Registered Nurse First Surgical Assistant

- Surgical Care Practitioner

- Physician Assistant/Associate

- Nurse Practitioner

- Advanced Scrub Practitioner.

A search for grey literature was conducted on the role of the NMSA via professional associations and regulatory organisations for relevant documents such as curricula, position descriptions and position statements.

A third element of information gathering was to contact international NMSAs currently working within these roles or within the associations governing the roles. By way of a snowball effect, additional contacts were established from the United States of America (USA), the United Kingdom (UK), Canada and New Zealand. Approval from the University of Queensland's Human Research Ethics Committee (Approval No. 2015000084) was granted for the wider Higher Research Degree project.
Results

Findings of the review are presented via a summary of the NMSA role internationally with further discussion grouped according to each of the countries of focus in this review.

\section{An international overview of the NMSA}

The role of the NMSA is well established internationally. Terms to describe NMSAs can be divided into nursing specific and non-nursing specific role titles. For example, Nurse Practitioners and Registered Nurse First Assistants are terms exclusively used to describe a nursing role which may mirror an NMSA role. Roles not exclusive to nurses but not excluding them are Physician Assistants/Associates, Surgical Care Practitioners, Surgical First Assistants, Operating Department Practitioners, Certified Surgical Technologists and Certified Surgical First Assistants. Some of these roles appear in all countries while some are limited to a single country. The Australian roles of Perioperative Nurse Surgeon's Assistant, Nurse Practitioner and Physician Assistant were also investigated. Table 1 outlines a summary of the roles investigated.

\section{United States of America}

It is important to note that, in the USA, there is a degree of ambiguity around processes of licensure, certification and registration of NMSAs. While registration may appear to be a comprehensive process, it is the most laissez-faire form of regulation in this health care system. Certification and licensure both require the applicant to pass a 'board-approved education program and examination'; however, certification in order to practice may not be mandatory ${ }^{10}$.
Of the NMSA roles in the USA, the roles of the Physician Assistant (PA) and Nurse Practitioner (NP) have been positively represented in the media. In 2015, US News and World Report cited the NP role as the second-best career of the year with PA coming in at number ten ${ }^{11}$. As of 2013, there were over 100000 practicing NPs and over 80000 practicing PAs in the USA. While not all of these practitioners are in the perioperative context, they are wellrepresented in this area. In the US, NP programs started as a certificate qualification but are now rigorous and standardised at master's level ${ }^{12}$. There is a clear movement in the USA to further strengthen NP programs to a professional doctorate level of education. NPs must pass a licensure exam to practice and in the USA are autonomous in their practice ordering investigations, treatments and pharmaceuticals ${ }^{13}$

Typically, entry into the PA program stipulates a graduate degree as a minimum entry requirement in the USA, although not necessarily with a health care emphasis ${ }^{14}$. Four PA organisations within the USA have collaborated to produce national PA competencies ${ }^{15,16}$. Licensure is given by individual states for services related to ordering investigations, prescribing, treatment and billing. All USA states and territories (except Puerto Rico) have laws regulating PA practice $^{17}$.

Registered Nurse First Assistant (RNFA) is another role similar to NMSA, with most RFNAs working under the direction of a surgeon or health care provider ${ }^{18,19}$. All state boards recognise this role but certification is voluntary ${ }^{20,21}$. Scope, remuneration, regulation and legislation are inconsistent from state to state ${ }^{22}$. This role does not possess the same level of autonomy as the NP and PA. 


\begin{tabular}{|c|c|c|c|c|c|c|c|c|c|}
\hline Role & $\begin{array}{l}\frac{2}{ \pm} \\
\frac{5}{\vec{J}} \\
0 \\
\dot{U}\end{array}$ & 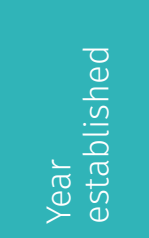 & 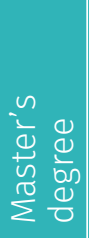 & 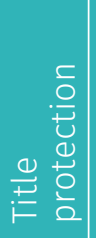 & 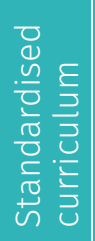 & 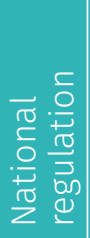 & 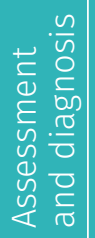 & 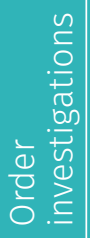 & 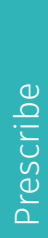 \\
\hline \multirow{5}{*}{ Nurse Practitioner } & USA & $1960 s$ & Y & Y & Y & Y & Y & Y & Y \\
\hline & CA & 1967 & $Y$ & $Y$ & $\mathrm{~N}$ & $\mathrm{~N}$ & Y & $Y$ & $Y$ \\
\hline & UK & $>20$ years & N & N & N & N & Y & Y & $E$ \\
\hline & NZ & 1998 & Y & Y & Y & Y & Y & Y & Y \\
\hline & $A U$ & 2000 & Y & Y & Y & Y & Y & Y & Y \\
\hline \multirow{4}{*}{ Physician Assistant } & USA & 1967 & Y & Y & Y & Y & Y & Y & Y \\
\hline & CA & 2006 & N & Y & $\mathrm{N}$ & N & $\mathrm{N}$ & N & Y \\
\hline & UK & 2004 & Y & N & Y & N & $\mathrm{N}$ & Y & $\mathrm{N}$ \\
\hline & $\mathrm{AU}$ & 2011 & N & $\mathrm{N}$ & $\mathrm{N}$ & N & Y & Y & Y \\
\hline \multirow{3}{*}{ Registered Nurse First Assistant } & USA & 1989 & Y & $\mathrm{N}$ & $\mathrm{N}$ & N & N & N & $\mathrm{N}$ \\
\hline & CA & 1990s & N & $\mathrm{N}$ & $\mathrm{N}$ & $\mathrm{N}$ & $\mathrm{N}$ & Y & $\mathrm{N}$ \\
\hline & NZ & 2014 & N & N & $\mathrm{N}$ & N & $\mathrm{N}$ & N & $\mathrm{N}$ \\
\hline $\begin{array}{l}\text { Certified Surgical Technologist / Certified Surgical } \\
\text { First Assistant }\end{array}$ & USA & 1969 & $\mathrm{~N}$ & $\mathrm{~N}$ & $\mathrm{~N}$ & Y & $\mathrm{N}$ & N & $\mathrm{N}$ \\
\hline Surgical Care Practitioner & UK & 1980s & Y & $\mathrm{N}$ & Y & Y & $\mathrm{N}$ & Y & $E$ \\
\hline Surgical First Assistant & UK & 2003 & $\mathrm{~N}$ & $\mathrm{~N}$ & $\mathrm{~N}$ & Y & $\mathrm{N}$ & N & $\mathrm{N}$ \\
\hline Operating Department Practitioner & UK & 1970 & N & $\mathrm{N}$ & N & Y & $\mathrm{N}$ & N & $\mathrm{N}$ \\
\hline Perioperative Nurse Surgeon's Assistant & $A U$ & 2001 & $\mathrm{~N}$ & $\mathrm{~N}$ & N & $\mathrm{N}$ & Y & N & $\mathrm{N}$ \\
\hline
\end{tabular}

Table 1: Overview of the education and autonomy of the Non-Medical Surgical Assistant role in Australia (AU), Canada (CA), New Zealand (NZ), the United Kingdom (UK) and United States of America (USA)

$\mathrm{Y}=\mathrm{Yes}, \mathrm{N}=\mathrm{No}$, Extra = Extra Education Required

A dual role has emerged in the USA of the Acute Care Nurse Practitioner / Registered Nurse First Assistant (ACNP/RNFA). This gives the practitioner the legislative authority to practice in an autonomous capacity and the required technical skills to first assist in the intraoperative phase ${ }^{19}$.

Roles unique to the USA are the Certified Surgical Technologist (CST) and Certified Surgical First Assistant (CSFA). These roles do not require any tertiary or nursing qualification for entry. Vocational qualifications vary from certificate to diploma to associate degree ${ }^{20,23}$. Scope of practice of these roles can include, scrubbing or instrument 'nurse', first or second assistant or circulating duties $^{23,24}$. The majority of health care institutions require certification as a condition of gaining credentialing as a Surgical First Assistant ${ }^{23}$.

\section{Canada}

Three NMSA roles were identified in Canada: Physician Assistant (PA), Nurse Practitioner (NP) and Registered Nurse First Assistant (RNFA). The only role not requiring candidates to be Registered Nurses is the PA.

While about 50 per cent of PAs work in primary care, the remainder work in specialty areas such as surgery ${ }^{25}$.

All four PA programs offered in Canada are accredited through the Canadian Medical Association Conjoint Accreditation process. PAs and NPs in Canada are able to prescribe medication ${ }^{26,27}$.

The title of NP is protected in Canada and educationally they are prepared at master's level plus internship. NPs practice independently within the perioperative area ${ }^{27}$.

Unlike PAs and NPS, RNFAs in Canada do not have a nationally standardised educational requirement, are not recognised as Advanced Practice roles and are governed as Registered Nurses $^{28}$. The RNFA is awarded a 'certificate of completion' or graduate certificate at the conclusion of the programs currently offered in Canada ${ }^{29}$.

\section{United Kingdom}

Roles identified in the UK include Surgical Care Practitioner (SCP); Surgical First Assistant (SFA), formally known as Advanced Scrub Practitioner; Scrub Practitioner; Operating Department Practitioner (ODP); Physician's Associate (PA), which is synonymous with Physician Assistant in other countries; and, finally, the Nurse Practitioner (NP). 
The only NMSA role in the UK that is exclusive to nurses is the NP role ${ }^{5,7,13,27,30-33}$. Most roles require a nursing or allied health background with the exception of the ODP which does not require any formal tertiary qualifications but does require school achievements for entry ${ }^{33}$. NPS and SCPs in the UK can prescribe medication and order investigations, and embody a more autonomous, care provider. However, the program for nurses to attain prescribing rights is rigorous and only undertaken if a need for these rights can be demonstrated ${ }^{34}$. PAs in the UK are currently awaiting legislation to be passed for permission to prescribe ${ }^{27}$. It is unclear how many PAs in the UK work in a perioperative role although one of the university websites does offer 'surgery' as a potential employment opportunity.

The ODP has evolved and changed names over a long period of time. Historical accounts of this role from the $18^{\text {th }}$ and $19^{\text {th }}$ century used titles such as 'handlers' or 'surgerymen'. In 1947 St Thomas's started training 'theatre technicians'; however, the Lewin Report (1970) on operating theatre personnel shortages was a crucial event for the development of ODPs ${ }^{35}$. With additional education, ODPs do work as first assistant to the surgeon ${ }^{36}$.

Unfortunately, the title of NP is not protected in the UK and this leads to ambiguity with scope of practice being dictated by job description rather than national competencies or standards for practice. There is no national minimum educational requirement or set curriculum and so education supports the NPs specialisation to fill clinical gaps ${ }^{13,27}$. It is difficult to establish what volume (if any) of NPs in the UK work in the NMSA role.

The Perioperative Care Collaborative (PCC) in the UK has identified three tiers of $\mathrm{NMSAs}^{5}$. In contrast to the role and curriculum of the NP in the UK the SCP role and curriculum is highly structured with the Royal College of Surgeons contributing to the development of this role and endorsing the curriculum ${ }^{5,37,38}$. A master's degree is now accepted practice for the SCP role ${ }^{7,39}$. The SCP has a more invasive role than the role of the SFA. The SFA does not perform any surgical intervention and works under direct supervision of the surgeon ${ }^{40}$. The PCC strongly recommends that entry to all academic programs for the roles of SCP and SFA be limited to applicants who are registered health care professionals but not exclusively nurses. Arguably, the most limited scope of practice of an NMSA is that of the Scrub Practitioner. This role is equivalent to an instrument nurse who provides limited surgical assistance for minor cases only 5 .

\section{New Zealand}

The role of the NMSA is at an early stage in New Zealand. A pilot initiative involving the role of the Registered Nurse First Surgical Assistant (RNFSA) was conducted in 2010-2011 and evaluated in 2011-2012. As a result of this evaluation, one course which is recognised by the Nursing Council of New Zealand is conducted at the University of Auckland. In 2015 this was offered as a three-phase graduate certificate, graduate diploma and master's degree specialising in Surgical Assist Nursing ${ }^{41}$. The framework and standards will be implemented nationally. Graduates have no facility to prescribe or order investigations. The role will be mostly performed in the intra-operative phase ${ }^{42}$. A pilot initiative and evaluation was also conducted for the role of Physician Associate and concluded in early $2015^{43}$.

Nurse Practitioners (NPS) in New Zealand must have completed a Nursing Council approved master's degree $26,27,34$. The perioperative NP's scope extended across a continuum of all perioperative phases ${ }^{42}$. The NP in New Zealand has role title protection by law and practices independently. Practice incorporates prescribing medication, interventions and treatments 27,34 .

\section{Discussion}

Of the two roles exclusive to nursing NP and RNFA - the NP role is the only one found in all countries discussed in this paper. In all of the countries except the UK, the NP title is protected, the curriculum is delivered at master's level and practitioners are required to demonstrate an expanded scope of practice across a range of practice domains including clinical assessment and diagnosis, testing, prescribing and treatment.

The role of RNFA is found in the USA, Canada and NZ. In contrast to the NP in these countries, the RNFA does not possess title protection. The education programs and the curriculums are not standardised at a national level and the clinician does not work in an autonomous manner.

Physician Assistants/Associates are represented in the USA, Canada and the UK but the role is most successful in the USA. In the USA, unlike Canada and the UK, the educational program is delivered at master's level with a standardised curriculum and national regulation. PAs in the USA can assess, diagnose, order investigations and prescribe medication; PAs in Canada and the UK cannot.

The SCP role, which only exists in the UK, is the only other role that has a master's level of education, a standardised curriculum and national regulation but the SCP does not possess the same autonomy as the NPS and PAs as previously explained.

\section{Implications for Australia}

The salient points from this review of the NMSA is that a tertiary education at master's level, a 
standardised curriculum and national regulation are the building blocks of an autonomous and professionally recognised NMSA role. The importance of education in underpinning role development and clinical safety is well established in the literature ${ }^{44-49}$.

In conjunction with these building blocks, the common denominator that the truly autonomous roles possess is title protection.

While scant literature suggests that only registered nurses are fulfilling the role of the NMSA in Australia, there has never been an audit of this role in Australia ${ }^{1,50-53}$. Ensuring the safe practice of clinicians is vital to the perioperative nursing profession $^{54}$. As the role of NMSA is gaining momentum in Australia it would be timely to establish an overview of the personnel who perform this role with a view to developing a nationally agreed curriculum and standards from which role evolution can occur in a coherent, cohesive manner.

\section{Conclusion}

Internationally, the roles performed by NMSAs are as distinct as the titles they possess. The various scopes of practice and degrees of autonomy that practitioners have is supported or constrained by legislation as well as policies and procedures that are institutional, state or nationally founded. What is highlighted in the literature is the divergence between the professional privileges and level of autonomy enjoyed by roles that have professional standing, supported by a standardised curriculum, title protection, national legislation and peak body recognition and governance, compared to the roles that lack these supports.

\section{Acknowledgments}

We would like to acknowledge the valuable input of the following associates: Julie Quick, Surgical Care
Practitioner, UK; Susan Hall, Surgical Care Practitioner, UK; David Melmer, Registered Nurse First Assistant, Canada; Josette Roussel, Senior Nurse Advisor Canadian Nurses Association; Yvonne Morgan, Course Coordinator Registered Nurse First Surgical Assistant, Auckland, New Zealand; Grace Groetzsch, Registered Nurse First Assistant, Canada; David Goddard, Registered Nurse First Assistant, USA; Matt Dubuc, Registered Nurse First Assistant / Nurse Practitioner, Canada.

\section{References}

1. Hamlin L, Dobson J, Cook L. Perioperative nurse practitioners (NP) - the first two perioperative NPS are authorised in NSW. ACORN J 2010;23(4):6-10.

2. Pulcini J, Jelic M, Gul R, Loke A. An international survey on Advanced practice nursing education, practice and regulation. J Nurs Scholarsh 2009;42(1):31-39.

3. Bryant-Lukosius D, DiCenso A, Browne G, Pinelli J. Advanced practice nursing roles: Developement, implementation and evaluation. J Clin Nurs 2004;48(5):519-529.

4. Jones A, Arshad H, Nolan J. Surgical care practitioner practice: one team's journey explored. J Perioper Pract 2012;22(1):19-23.

5. Hall SL, Quick J, Hall A, Jones A. Surgical Assistance - who can help? Ann R Coll Surg Engl 2014;96:244-246

6. Pickersgill T. The European working time directive for doctors in training. BMJ 2001;Dec:323-324.

7. Quick J, Hall S, Jones A. The Surgical Care Practitioner role problems and possible solutions from nurses in the UK offered to RNFSA colleagues in New Zealand. Dissector. 2014;42(1):32-34.

8. Van Der Weyden M. Task transfer: Another pressure for evolution of the medical profession. Med J Aust 2006;185(1):29-31.

9. Australian Bureau of Statistics. 'Doctors and nurses' in Statistics. ABS (editor); 2011.

10. Hoyle J. 'Regulation of Surgical Assistants and Surgical Technologists' in Joint Commission on Health Care Senate Bill 313. 2012

11. Graves J, McMullen L. The 25 Best Jobs of 2015. US Money and World Report. 2015.

12. Hooker R. Physician's assistants and nurse practitioners: The United States experience. Med J Aust 2006;185(1):4-7.

13. Morgan S. What are the differences in nurse practitioner training and scope of practice in the US and UK? Nurs Times 2010;106(27):21-24.

14. Health Workforce Australia 2012: The potential role of Physician Assistants in the Australian - Final Report. Adelaide: Health Workforce Australia; .2011.

15. Evaluation of the Queensland Physician Assistant Pilot - Final Report. Queensland Health: 2010.

16. Physician Assistants Historical Society. Physician Assistants Historical Society 2014 [cited 2014 Dec 30]. Available from: pahx.org/period08.html.

17. Hooker R, Muchow A. The 2013 census of licensed physician assistants. J Am Acad Physician Assist 2014;27(7):35-39.

18. HCPro. Clinical Privilege White Paper Registered Nurse First Assistant: HCPro; 2008 [cited 2014 Dec 30]. Available from: www.hcpro.com/content/254300.pdf.

19. Wadas T. Expanding the scope of acute care Nurse Practitioners with a Registered Nurse First Assist specialty. AACN Adv Crit Care 2008;19(3):261.

20. HC Pro. Clinical Privilege White Paper Scope of Practice for Surgical Technologist. HC Pro; 2011.

21. Competency and Credentialing Institute. About CRNFA Certification: Competency and Credentialing Institute; 2014[cited 2014 Dec 30]. Available from: www.cc-institute.org/ crnfa/certification/about.

22. Kunic RJ, Jackson D. Transforming nursing practice: barriers and solutions. AORN journal. 2013;98(3):235-248.

23. Surgical Assistant Resource. Surgical Assistant Education 2015 [2015 Mar 15]. Available from: www.surgicalassistantresource.org/index. php?p=1_5.

24. Association of Surgical Technologists. Association of Surgical Technologists 2014[cited 2014 Dec 30]. Available from: www.ast.org/AboutUs/About_AST.

25. Canadian Association of Physician Assistants. Canadian Association of Physician Assistants 2014 [cited 2015 Jan 12]. Available from: capa-acam.ca/features/faq.

26. Stasa H, Cashin A, Buckley T, Donoghue J. Advancing advanced practice - clarifying the conceptual confusion. Nurs Educ Today 2014;34:356-361

27. Mumford V, Haas M. Nurse Practitioners and Physician Assistants: Adapting models of care to changing demographics. University of Technology, Sydney; 2014[cited 2015 Jan 12]. Available from: refinephc.org.au.

28. MacDonald M, Schreiber R, Davis L. A discussion paper. Exploring new roles for advanced nursing practice. Canadian Nurses Association; 2005 
29. Mohawk College. Registered Nurse - First Assistant Graduate Certificate 2014 [cited 2014 Dec 30]. Available from: www. mohawkcollege.ca/continuingeducation/registered-nurse-first-assistantcertificate.html.

30. Quick J. The role of the surgical care practitioner within the surgical team. BJN 2013;22(13):759-765.

31. Kneebone RL, Nestel D, Chrzanowska J, Barnet AE, Darzi A. Innovative training for new surgical roles - the place of evaluation. Med Educ 2006; 40(10):987-94

32. Independent Healthcare Advisory Services. Surgical Care Practitioners Policy Statement. Independent Healthcare Advisory Services: 2006.

33. College of Operating Department Practitioners. Curriculum Document. College of Operating Department Practitioners; 2011.

34. Currie J, Edwards L, Colliban M, Crouch R. A time for international standards?: Comparing the Emergency Nurse Practitioner role in the UK, Australia and New Zealand. Accid Emerg Nurs 2007;15:210-216

35. Timmons S, Tanner J. A disputed occupational boundary: operating theatre nurses and Operating Department Practitioners. Sociol Health Illn 2004;26(5):645-666.

36. National Health Service. NHS Careers: What operating department practitioners do: National Health Service [cited 2014 Sep 29]. Available from: www.nhscareers.nhs.uk/ explore-by-career/operating-departmentpractice/what-operating-departmentpractitioners-do

37. Royal College of Surgeons of England. Surgical Care Practitioner 2014 [2015 Jan 2]. Available from: www.rcseng.ac.uk/surgeons/ training/accreditation/surgical-carepractitioners-scps.
38. Dean $\mathrm{H}$. The surgeons who are not doctors. BBC News. 2012.

39. Quick J, Hall S. Non-medical surgical assistants: a review. The Clinical Services Journal. 2014; June:75-78.

40. Perioperative Care Collaborative. Position Statement: Surgical First Assistant 2012 [cited 2015 Jan 2]. Available from: www.afpp.org.uk/careers/StandardsGuidance.

41. The University of Auckland. Postgraduate Nursing Registered Nurse First Surgical Assist: School of Nursing; 2014 [cited 2015 Jan 2]. Available from: https://cdn.auckland. ac.nz/assets/fmhs/son/postgrad/_docs/ RNFSA.pdf.

42. New Zealand Nurses Organisation. Registered Nurse First Surgical Assistant in Operating Theatres In New Zealand: Service Policy Guidelines. Wellington: New Zealand Nurses' Organisation; 2009.

43. Ministry of Health. Physician Associate 2014 [cited 2015 Jan 12]. Available from: www. health.govt.nz/our-work/healthworkforce/new-roles-and-initiatives/ current-projects/physician-associatephysician-assistant.

44. Russell K, Coventry T. Innovations in postgraduate work integrated learning within the perioperative nursing environment: A Western Australian experience. Journal of Perioperative Nursing in Australia 2016;29(4):15

45. Foran P. The value of guided operating theatre experience for undergradaute nurses. Journal of Perioperative Nursing in Australia 2016;29(1):10.

46. Duff J, Butler M, Davies M, Williams R, Carlile J. Factors that predict evidence use by Australian perioperative nurses. Journal of Perioperative Nursing in Australia. 2016:29(2):24
47. Wilson M, Johnson MA. The impact of the Postgraduate Certificate in Perioperative Specialty Nursing on individual participants, unit or service, and organisations. ACORN 2015;28(3):22.

48. Duff J, Butler M, Davies M, Williams R, Carlile J. Perioperative nurses' knowledge, practice, attitude, and perceived barriers to evidence use: A multisite, cross-sectional survey. ACORN J 2014;27(4):28.

49. Freeling $M$, Parker S, Breaden K. Exploring experienced nurses' views, attitudes and expectations of graduate nurses in the operating theatre. Journal of Perioperative Nursing in Australia. 2017;30(1):23

50. Lynn A, Brownie S. The perioperative nurse surgeon's assistant: Issues and challenges associated with this emerging advanced practice nursing role in Australia. Collegian 2014;22(1):109-115 [cited 2015 Feb 3]. Available from dx.doi.org/10.1016/j. colegn.2013.12.004

51. Bryant E. Perioperative Nurse Surgeon's Assistants in day surgery an emerging role within Australia's health system. Ambul Surg 2010(July):25-27.

52. Smith C, Hains T, Mannion N. An opportunity taken: Sunshine Coast University Private Hospital's Perioperative Nurse Surgeon's Assistant experience. Journal of Perioperative Nursing in Australia 2016;29(3):23.

53. Criscitelli T. Human factors engineering: Its place and potential in OR safety. Journal of Perioperative Nursing in Australia 2016;29(4):29.

54. Battie R, Steelman VM. Accountability in nursing practice: Why it is important for patient safety. Journal of Perioperative Nursing in Australia 2015;28(4):14

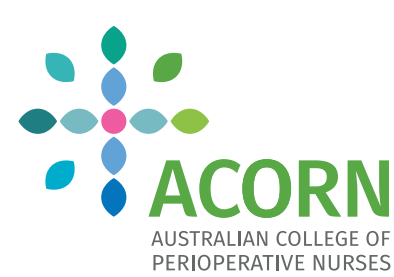
PERIOPERATIVE NURSES

\section{Seeking manuscript reviewers}

If you are a perioperative nurse from an academic, educational, managerial or clinical background you could join ACORN's manuscript review team.

For more information visit our website at www.acorn.org.au/journal/review-amanuscript.

If you would like to join our team of manuscript reviewers, please contact the ACORN Journal Editor on journaleditor@acorn.org.au or the ACORN office. 